This item was submitted to Loughborough's Research Repository by the author.

Items in Figshare are protected by copyright, with all rights reserved, unless otherwise indicated.

\title{
To cost an elephant: an exploratory survey on cost estimating practice in the light of product-service-systems
}

PLEASE CITE THE PUBLISHED VERSION

http://dx.doi.org/10.1080/1941658X.2015.1016588

PUBLISHER

(C) Taylor and Francis

\section{VERSION}

AM (Accepted Manuscript)

\section{PUBLISHER STATEMENT}

This work is made available according to the conditions of the Creative Commons Attribution-NonCommercialNoDerivatives 4.0 International (CC BY-NC-ND 4.0) licence. Full details of this licence are available at: https://creativecommons.org/licenses/by-nc-nd/4.0/

\section{LICENCE}

CC BY-NC-ND 4.0

\section{REPOSITORY RECORD}

Settanni, Ettore, Nils E. Thenent, Linda B. Newnes, Glenn Parry, and Yee M. Goh. 2019. "To Cost an Elephant: An Exploratory Survey on Cost Estimating Practice in the Light of Product-service-systems". figshare. https://hdl.handle.net/2134/17068. 


\section{To cost an elephant: An exploratory survey on cost estimating practice in the light of Product-Service-Systems}

Businesses now contracting for availability are regarded as part of a paradigm shift away from the familiar 'product and support' business model. The main difference being that such businesses eventually commit to provide a service outcome via Product-Service-System (PSS). The research presented in this paper investigates how current cost estimating practice relates with the idea of having as the point of focus for the analysis a PSS delivering service outcomes, rather than a product. Since the topic is in its infancy, an exploratory survey was designed and circulated via the Internet amongst practitioners with the aim of looking for initial patterns, ideas and hypotheses, rather than to confirm existing ones. The picture that seems to emerge is that respondents would not necessarily see the representation and modeling of a PSS as being a precondition to estimate the cost of the service it provides. In line with most academic literature, respondents would rather consider the cost of providing a service via PSS as conceptually equivalent to the cost of the in-service stage of a durable product. Although now allowing for generalization, this research reveals paths that may be worth exploring further.

Keywords: product-service-systems (PSS); availability contracts; cost estimating; exploratory research; Internet survey. 


\section{INTRODUCTION}

A renowned version of a universally known fable features several blind men who try and figure out what an elephant looks like ${ }^{1}$. As each in turn approaches the animal and touches a different part of it, he concludes that the elephant has the appearance of that part - be it smooth and sharp as a spear, mighty and plain as a tree, broad and sturdy like a wall and so on. The men dispute "loud and long” without coming to an agreement as to the elephant's appearance: though each is partly in the right, all are in the wrong!

The 'elephant' of interest here is a Product Service Systems (PSS). PSS is a construct used to emphasize that products and services are entangled within a knowledge-intensive sociotechnical system aimed to enable the customer to attain beneficial service outcomes, or value ‘in-use’ (Meier, Roy, \& Seliger, 2010). A specific type of PSS operates under availability or performance-based contracts whereby manufacturers commit to ensure the usability of the physical assets acquired by their customers. For example, under a wholeaircraft availability-contract the customers' needs are met when a fighter jet is on the apron in a fit state for the women and men of the national air force to fly it (BAE Systems, 2009). Especially in defence aerospace availability contracts are regarded as an alternative to a business model where handing over the equipment to the customers and providing aftersales support constitute distinct responsibilities and potential streams of revenue (Caldwell \& Settle, 2011).

The representation and modeling of a PSS and the evaluation of the cost of the service outcome(s) delivered by a PSS are different angles from which insight about the same

\footnotetext{
${ }^{1}$ The fable, titled "the blind men and the elephant", can be found in Saxe, JG. 1868. The Poems of John Godfrey Saxe. Boston: Ticknor and Fields, pp. 259-261 [digitalised by Google].
} 
phenomenon can be provided. Recent works summarize the academic literature on the topic with a focus on either PSS modeling or cost evaluation (Cavalieri \& Pezzotta, 2012;

Phumbua \& Tjahjono, 2012; Settanni, Newnes, Thenent, Parry, \& Goh, 2014; Tukker, 2013; Vasantha, Roy, Lelah, \& Brissaud, 2011).

An aspect seldom addressed in the literature is whether representing and modeling a PSS is a precondition to provide a meaningful estimate of its service outcomes’ cost. From a critical reading of the existing reviews one has the opposite impression: PSS modeling and costing tend to be carried out separately, and underpinned by concepts and assumptions that are different and sometimes contradictory. Hence, much like the men in the fable, scholars coping with designing, modeling and costing in the context of PSS seem content with the evidence gained from experiencing partial aspects of 'the beast'.

The research presented in this paper aims to provide a preliminary investigation of practitioners' attitude towards the idea that representing and modeling a PSS is a precondition to provide a meaningful estimate the cost of the service it provides. To this purpose an Internet survey amongst an on-line community of practitioners was carried out. Previous surveys about PSS have focused on aspects related to the use Information and Communication Technology within the firm (Belvedere, Grando, \& Bielli, 2013; Hernandez-Pardo, 2013) and were not Internet surveys. Since there is no comparable study on the topic, the research presented in this paper sets out to look for new patterns, ideas, or hypotheses and reveal paths that may be worth exploring further rather than attempting to confirmation existing ones, hence it classifies as exploratory (Vogt, 2005). Internet surveys work well for exploratory research (Sue \& Ritter, 2007). 
Internet surveys have become an essential tool for a wide range of research fields mostly due to benefits such as the absence of interviewers; the possibility for the respondents to complete the questionnaire at the time, place and pace which is most convenient to them; and the provision of data that are immediately storable and ready for further processing (Vehovar \& Lozar Manfreda, 2008). However, due to the relative novelty of this type of survey limitations arise. Compared to more traditional surveys, the response rates usually do not favour Internet surveys (Manfreda, Berzelak, Vehovar, Bosnjak, \& Haas, 2008), and the sampling methods are not developed enough to provide data that are projectable to general populations (Best \& Harrison, 2009).

The remainder of the paper is as follows. The next section identifies some concepts and assumptions underpinning the representation and modeling of PSS, and the current cost estimating practices. It is followed by an outline of the choices underpinning how the survey was designed, conducted and analyzed. The limitations encountered are also highlighted. Then the findings from the results of the analysis of both quantitative and qualitative data gathered through the survey are shown and discussed. The paper closes providing directions regarding paths that may be worth exploring in future research.

\section{BACKGROUND}

A crucial aspect for the representation and modelling of a Product-Service System (PSS) is its qualification as a ‘system’. Broadly speaking, a system is a combination of interacting elements organized to achieve a stated purpose (BS ISO/IEC, 2002). In the specific case of a PSS, the system of interest is socio-technical in nature (Meier et al. 2010), that is, social and technical elements are entangled within a broader transformation system. Although the concept of system is somehow embedded in that of PSS, the qualification of a PSS as a 
'system' has received only scant attention so far when it comes to modelling (Cavalieri \& Pezzotta, 2012).

Following Baines \& Lightfoot (2013), under availability-based contracts the system of interest is the delivery system which underpins the provision of an 'advanced service'. An advanced service is a type of service which is critical to their customers' core business processes; and the underpinning delivery system is just as important as the service offering itself. Hence, a PSS is to an advanced service as a manufacturing system is to a product. From a cost evaluation perspective, an advanced service provider is concerned with the cost of delivering a result via PSS (Tukker \& Tischner, 2006). Settanni et al. (2014) review the literature extensively and conclude that in the absence of a formalized qualification of a PSS as a 'system' and a clear identification of the intended final outcome meant to be pursued by the work of a PSS the question 'how much does it cost to deliver such an advanced service as availability under a performance or availability-based contract?' tends to be substituted with 'what are the disbursements accumulated during the in-service stage of a repairable physical asset which stochastically fails and is restored to operation?'. In this sense, there is no substantial difference between newly proposed computational approaches meant for use in PSS and those employed in a 'product and support' business model. For example, Datta \& Roy, (2010) suggest a framework which is centered on the cost breakdown structure of a stand-alone service, not on a PSS; Similarly Huang, Newnes, and Parry (2012) evaluate cost estimation techniques at the individual service level. Although without specific reference to a PSS, a 'system' approach is often claimed in cost estimation. However it is not always clear how the system nature of the phenomenon of interest affects the way cost evaluation is carried out - see, for example Wang, Valerdi, 
Roedler, Ankrum, and Gaffney (2012); Valerdi (2011); Hart, He, Sbragio, and Vlahopoulos (2012).

When service is identified with providing after-sale support to a product, technical knowledge about individual products involved within a PSS is used to infer the service cost directly, especially at the design stage (see e.g., Roy \& Erkoyuncu, 2011). This approach is common in a 'product and support' business model but, as demonstrated for space programs, it may easily sacrifice engineering insight to provide a 'one off' cost figure that will get approval, e.g. for budgeting purposes (Keller, Collopy, \& Componation, 2014). Tukker (2013) highlights that the transition from selling product and after-sales support to a PSS-oriented business may require “a totally different skill set and organization”. If the point of focus for the analysis of cost is a PSS delivering service outcomes, rather than a product, it seems legitimate to ask whether and to what extent the skills and knowledge in cost estimating need to be enriched, too.

Taking an aircraft as an example Figure 1 shows that, in principle, cost estimating is a knowledge intensive activity which transcends the boundaries of the individual disciplines involved- see Curran, Raghunathan, and Price (2004).

\section{Insert Figure 1 HERE}

A typical cost estimating process will include interaction of technical, business or financial specialties and accounting, mathematical or statistical skills (Stewart, 1982; Amos, 2004). However, these interdisciplinary skills seem to be expected to coexist within the individual cost estimator. In other fields, for example design, collaboration among experts to grasp multi-faceted problems as, for example, in whole system visualization is explicitly discussed (Charnley, Lemon, \& Evans, 2011). 
In practice, “...cost is viewed as a relatively simple thing, to be resolved in the course of a design or development project, but certainly not one that should be at the center of the engineering effort” (Field, Kirchain, \& Roth, 2007, p. 22). A recurrent assumption is that a cost estimate can and should be generated in the absence of an understanding of the product, the methods of manufacture/process and relationships between processes (Roy, 2003). Typically, the knowledge and expertise embedded in individuals concerning the factors involved in a cost estimate are used to derive rule-based inference systems to assess the "goodness of fit" of a cost estimate (Serpell, 2004). For example a survey showed that in the UK construction sector project cost estimating is regarded as a multi-disciplinary function involving engineering, financing and management decisions (Akintoye \& Fitzgerald, 2000). The same survey highlights that the lack of practical knowledge of the construction processes by those responsible for the estimating function is perceived as a major shortcoming. Similarly, lack of knowledge about the manufacturing process is mentioned as one of the difficulties associated with product costing (Jiao \& Tseng, 1999). This overview led to the following research questions:

- RQ1: Is representing and modeling a PSS perceived as a precondition to provide a meaningful estimate the cost of the service it provides?

- RQ2: Is there a counterpart in current cost estimating practice of the system approach which underpins the representation and modelling of a PSS?

- RQ3: Do cost estimators use their knowledge about the underpinning service delivery system -a PSS - along with data on product-related features?

These research questions were investigated following the methodology described in the next section. 


\section{METHODOLOGY}

In order to understand how the current cost estimation practices may relate to the concept of PSS and which challenges may raise an internet-user community of international practitioners was surveyed. These individuals represent the unit of analysis in the study (Blessing \& Chakrabarti, 2009). The following subsections discuss the underlying research strategy, how the survey was designed and conducted, and also provide some caveats regarding the analysis of the data gathered.

\subsection{Research strategy}

Based on the assumption that there is a community of cost estimators that share common views, and that cost estimation is a task that can be distinguished from other tasks within an organization, a survey using questionnaires was considered suitable (Hawkins \& Orlady, 1993).

A computerized self-administered questionnaire on a Web-based survey host was chosen as the data collection method as it enables coverage of a relatively large number of respondents if compared to one-to-one interviews. A word of caution, however, is necessary. Although the sample size in online survey research may sound as potentially extremely large, it can be extremely difficulty to construct good sampling frames due to the nature of the Internet (Blank, 2008; Denscombe, 2010). Not only is a 'good' sampling frame relevant to the research topic, but also but also complete, precise and up-to-date (Denscombe, 2010). Hence, one of the main disadvantages of using Internet surveys is that the data produced are hardly projectable to draw conclusions about general populations (Best \& Harrison, 2009; Sue \& Ritter, 2007). 
Since no finite sample exists, transmission of the online data collection instrument to the appropriate respondents is a crucial step (Best \& Krueger, 2008). Ideally, contacting respondents by e-mail first favors greatest response to online surveys but requires access to appropriate e-mail lists (Sue \& Ritter, 2007). Initially, the researchers have attempted to obtain lists directly from an association of professionals with interests and experience in cost analysis and forecasting. Using the organization's list was not possible, however, due to the sensitivity of the data. The alternative was to advertise the survey in a representative internet-user community, namely the members of cost estimating/cost engineering LinkedIn groups, to direct potential respondents to the Web-based survey host. These forums were deemed adequate to provide access to a purposive sample of people that most likely have the expertise to provide quality information and valuable insights, thus allowing the researchers to concentrate on instances which would best illuminate the research questions at hand (Denscombe, 2010).

As Sue and Ritter (2007) point out, the alternative to direct e-mail contact used here reduces the benefits of speed and efficiency compared to having an existing list, and may raise validity concerns due to respondents self-selection into the study. However, since it is not unusual for internet surveys to be based on general invitations to follow a link to the survey, they are almost inherently related to a non-probability sample, and to a sample selection bias which is outside the researchers’ control (Vehovar \& Lozar Manfreda, 2008).

\subsection{Questionnaire design}

The questionnaire consisted of four categorical variables each describing age, gender, sector and expertise; 23 Likert-type (standard 5-points “agree-disagree” ordinal categories) statements (items); and one "tick all that apply" statement. For each statement the 
respondent was provided with a non-mandatory free text field to comment on their answer. A summary of the questionnaire is provided in APPENDIX I.

Likert scaling is a widely employed method for assessing attitude, opinion or perception by scoring a series of items, each consisting of a statement to which the respondent is asked to react, and a response scale (Barnette, 2007).

In the case considered here, the items were specifically designed around the research questions. The questionnaire combined concepts and assumptions that underpin the representation and modeling of a PSS with those that underpin product-centric cost estimation. Participants’ responses have been associated with such values that:

- A favorable disposition towards having PSS delivering service outcomes as the point of focus for the analysis has higher score;

- A favorable disposition towards product-centric view had lower score.

Some items (namely: Q04; Q05; Q06; Q07; Q09; Q14; Q19; Q20; Q22; and Q24) have been phrased in the semantically opposite direction to help prevent response bias. These items had to be reverse-scored prior to the analysis in order to make them comparable to the other items (Weems, 2007).

The choice of target respondents and to design the questionnaire as described created a situation likely to disconfirm the ideas underpinning the research questions. This practice can be useful for generalization purposes when a non-statistical sampling approach is used, as it gives the researchers the best chance of falsifying their argument (Blank, 2008). Ideally, the survey questions should be unambiguous, and meaningful to the respondent (Bryman, 2012; Sue \& Ritter, 2007). To this purpose the researchers have engaged in an interactive process which involved a survey expert and graduate students familiar with the 
topic of cost estimating within one of the institutions the researchers belong to. However, as Sue and Ritter (2007) put it “...no textbook can cover all the ways respondents may misinterpret your questions”. Running a pilot with a small group of respondents in a real life situation is deemed good practice which may play favorably in terms of response rates (Shih \& Xitao Fan, 2008). Hence, a small scale pre-test study was carried out during an event organised by a professional association operating in the field of cost estimation and cost engineering for the association's members. Responses were collected from attendants who volunteered to complete the survey online from laptops provided by the researchers. The presence of two researchers allowed those who wished to feed-back soon after the questionnaire completion. Participants were also provided with a glossary with definitions of key terms such as 'system' and 'product-service-system (PSS)'. The pilot led to a questionnaire with a slightly revised terminology and structure. More self-contained statements were deemed necessary since it seemed that respondents would not take a glossary into account. This has not affected positively the length of some questions. Finally, the uniformity and usability of the internet data collection instrument in the response environment is an important aspect (Best \& Krueger, 2008). To this purpose the researchers chose to subscribe to the services of a commercial survey software tool capable to support different internet browsers.

\subsection{Analysis}

From the end of June 2012 to the end of January, 2013 a total of 132 participants volunteered to entered the survey, 98 of which completed the survey in full. Respondent's information is summarized in Figure 2, whilst the answers to the 'tick all that apply' are summarized in Figure 3. 


\section{Insert Figure 2 here}

\section{Insert Figure 3 here}

As specified earlier, the online community has not been used here as a sampling frame, rather, as a way to advertise the survey. Hence it would not make much sense to use the whole umber of members that joined such communities as a proxy for the number of 'eligible’ units investigated. For the same reason, however, the self-selection of respondents may raise a validity issue, as mentioned earlier.

The main use of a response rate is as a measure of how well the survey results can be generalized, but generalization is not the aim of this exploratory research presented here (besides being inherently problematic when employing internet surveys, as shown by the literature). Rather, responses from a non-probability sample such as the one adopted here can be still useful in developing hypothesis in exploratory research: according to Fricker (2008) “...simply because a particular method does not allow for generalizing beyond the sample does not imply that the methods and resulting data are not useful in other research contexts”.

Finally, good practice demands that to avoid response bias researchers should find out if respondents are different from non-respondents in some way that is relevant to the survey (Denscombe, 2010). However, it seems that there is no way to assess nonresponse bias in internet surveys due to lack of information about those that choose not to complete a survey (Fricker, 2008).

Having these caveats in mind, the data gathered directly from the online survey instrument were analyzed. To capture insight from both the Likert-type items and the free text field, the former have been investigated through a quantitative approach, the latter through a 
qualitative approach. This practice is often referred to as simultaneous mixed methods (Denscombe, 2010). The outcomes of these analyses are shown in the next section.

\section{FINDINGS}

\subsection{Findings from quantitative data analysis}

Descriptive statistics for the gathered data are presented in Table 1.

\section{$\underline{\text { Insert Table } 1 \text { here }}$}

Likert items are categorical ordinal variables, although they are often implicitly treated as continuous for analytical purposes. Since the outcomes of categorical variables may be coded as number but are not numbers one should not ask for mean, standard deviation and skewedness. Rather, the frequency of occurrence for each value, the median or the mode, and the Inter Quartile Range (IQR) are more appropriate (Harvey, 1998; Pallant, 2010). Mode and IQR for each Likert item can be represented graphically via Box Plots (Massart, Smeyers-Verbeke, Capron, \& Schlesier, 2005) as shown in Figure 4.

\section{Insert Figure 4 here}

Each Box Plot in Figure 4 has been generated using the statistical software SPSS. It represents the variation in the sample of responses to each Likert item without making assumptions about its underlying statistical distribution, rather, through their quartiles. The median (second quartile) is shown as a band within the each box, whilst variability outside the third and first quartiles (top and bottom of the box) is indicated by lines extending vertically. The 'shorter' the box, the less variation in the data. In Figure 4 outliers are plotted as individual points (stars if extreme outliers).

In order to explore the to Likert responses Principal Component Analysis-PCA was adopted. PCA is a statistical technique used to trim down variables that may be measuring 
the same construct and hence are interdependent, or significantly correlated (Coleman, 2010; Dunteman, 1989). Sometimes these clusters, or principal components, are identified upfront by the researchers, and confirmed via PCA or similar analyses. Examples are the distinctive consumer attitudes towards music purchasing in Parry (2012) or the aspects of defense projects that assumedly affect using Life Cycle Costing in Tysseland (2008). This, however, is not the case for the research presented in this paper, due to its exploratory nature.

PCA is often carried out by making implicit assumptions on the distribution of the variables being investigated especially if analysis is undertaken via SPSS (Field, 2005; Pallant, 2010). Here, polychoric correlation has been used to avoid making such assumptions upfront, and to prevent the correlation coefficients from being underestimated (Panter, Swygert, Grant Dahlstrom, \& Tanaka, 1997). Other examples in which a similar approach is used include Battisti and Stoneman (2010). The statistical software R (R Development Core Team, 2012) was employed to generate polychoric correlations via the "polycor" package (Fox, 2010).

To facilitate factor's interpretation the Varimax option for factor rotation was selected in SPSS due to the absence of expectations about how well the items of the questionnaire inter-correlate. As an empirical rule, loading of each variable onto a certain factors above 0.512 is deemed adequate for a sample of 100 (Field, 2005). The number of components or factors to be retained has been determined through the use of Parallel Analysis (Watkins, 2006). A Cronbach's Alpha of 0.6 has been used as an acceptable measure of the reliability of the scale composed by the questions that cluster together under each component 
(although values above 0.7 are typically sought, for exploratory research a lower value is also accepted - see e.g. (Tysseland, 2008).

The exploratory PCA led to the identification of three components shown in Table 2. The topic underlying each factor indicated in Table 2 has been deduced from the contents of the questions that loaded onto that factor.

\section{$\underline{\text { Insert Table } 2 \text { here }}$}

To the low reliability scores obtained, the identified components are used here as an attention focusing device, to explore possible conceptual links between different items of the survey that are determined by the answers given, and that may be worth being further explored in future research.

\subsubsection{Cluster 1: Product is the point of focus to estimate cost}

The first cluster in Table 2 seems to refer to a favorable disposition of the respondents toward focusing on a product and its feature, rather than on the broader transformation system a product may be part of.

The crucial item in this cluster is Q16, as 72\% of respondents put the emphasis on a product for cost estimation purposes even when a PSS is, in fact, involved. Item Q16 clusters with items that confirm more traditional viewpoints on product cost estimating, such as:

- A concept of 'Through-life costing' which is strongly identified with a product's reliability (86\% agreed or strongly agreed with the statement in item Q15);

- The features of a stand-alone product act as the point of focus for the evaluation of cost, hence 'service' tends to be identified with providing after-sale support to a product (circa 82\% agreed or strongly agreed with Q12 and Q13); and 
- Analysis driven by data rather than by theory or 'first principles' (84\% agreed or strongly agreed with Q01), and conducted by techniques tailored around the idea of product life-cycle (83\% agreed or strongly agreed with Q17).

\subsubsection{Cluster 2: 'System' is a synonym for 'product'}

The second cluster in Table 2 seems to indicate a favorable disposition toward the concept of 'system' which, however, turned out to be a problematic concept to deal with as it tends to be most commonly applied as a synonym for 'product', and hardly associated to the broader transformation system to which it contributes. The central item in this cluster is Q11, which suggests the idea that underpinning a service is a system of interlinked activities (the service delivery system) and that this system plays a role in the evaluation of the service's cost: 59\% endorse this view. This item clusters with items that were meant to investigate to whether system representation and modeling play a role in cost estimation. For example, when specific techniques for the diagrammatic representation of a system are mentioned, only $42 \%$ of respondents acknowledge that system representation and cost estimation are not two intellectual silos (Item Q02). Item Q04 is analogous to Q11 but with a product acting as a point of focus, in which case $86 \%$ of respondents agrees or strongly agrees. Almost $90 \%$ of respondents agreed with Item Q07 suggesting that, at least in principle, there is an interest from the practitioners for the broader context in which a cost estimate is generated. Respondents also deem beneficial integrating system modelling with cost estimating if a PSS is investigated (82\% agree or strongly agree with Item Q14). By contrast, the respondents are almost symmetrically divided went it is suggested that, unlike Item Q11, knowledge the service delivery system can be reduced to knowledge about a product in-service (Item Q03). Respondents are similarly divided when it is 
suggested that at the early design stage knowledge about the product can be reduced to knowledge about its features (Item Q08); as well as when, in contrast to Q04, a partial focus on a product's life cycle is suggested (Item Q23).

Finally, since $80 \%$ of respondents agrees or strongly agrees with Item Q10 it seems that the concept of systems is mostly associated to a hierarchical architecture of the physical entities involved, what Bartolomei, Hastings, Neufville, and Rhodes (2012) define as the technical domain of System Engineering.

\subsubsection{Cluster 3: Going about a cost estimate requires knowing about a product}

The last cluster seems to group responses to items that target how the respondents go about building up an estimate. The central item for this cluster is Q06, which challenges the respondents to 'give up’ a familiar set of data about products if they are provided with insight about the broader transformation system those products are part of. Only $26 \%$ considers the insight about the PSS superior in order to perform their estimate.

Some items in this cluster highlight the peculiarity of dealing with a service delivery system. For example, 65\% of respondents acknowledge that insight into delivering a service and evaluating its cost cannot be achieved solely by means of historical data (Item Q05). The respondents are symmetrically divided, however, when it comes to chose whether or not to estimate the cost of a PSS by adding the estimated cost of the product involved to the estimated in-service support cost for that product, as they would be doing in a product-centric, traditional Through-life costing anyway (Item Q09). By contrast, 78\% of respondents agree or strongly agree with Item Q24 that tangible products and activities form a system meant to achieve a common purpose (the service outcome). 
Also within this cluster are items related to traditional product cost estimation revealing that priority is accorded to the generation of a cost figure, over questioning the underpinning methodological and computational aspects. For example, cost figures generated on heterogeneous grounds are deemed comparable (Item Q19). Respondents, however, are divided on the well known assumptions, seldom questioned in practice, that most product costs are locked in at design (Item Q20), and so are they when asked this assumption unjustifiably shift attention away from actions that can be taken outside the design silo (Item Q22).

\subsection{Difference between groups}

A Kruskal-Wallis test has been chosen to explore possible differences between groups whilst relaxing the assumption commonly made in parametric approaches, such as twoways analysis of variances that the underlying distribution of scores in the population from which the sample is drawn is normal. The test revealed no statistically significant differences in the above mentioned scores across groups defined by 'Gender', 'Age', 'Expertise' and most of the ‘tick all that apply’ options in Q18 (see Appendix). However, the test revealed:

- A significant difference in the disposition toward system understanding through reduction/isolation across sectors, $\chi^{2}(12, n=97)=20.657, p=.056$. An inspection of the mean ranks suggests that the group 'Other service activities' recorded a higher median score $(\mathrm{Md}=37)$ whilst 'Real estate activities' recorded the lowest $(\mathrm{Md}=25)$;

- A significant difference in the disposition toward the adaptation of feature-cantered methods in cost estimations across those thinking that the "availability of software 
packages” and “computations following well-known mathematical rules” are the most important aspects for selecting the cost estimating techniques to be used, respectively $\chi^{2}(1, n=97)=5.326, p=.021$; and $\chi^{2}(1, n=97)=12.575$, $p=.000$. An inspection of the mean ranks suggests that the group that did not picked up these options recorded a higher median score $(\mathrm{Md}=12)$.

\subsection{Additional findings from the free text fields}

Free text comments provide additional insights into the respondents' opinions and why a certain answer was given, thus complementing quantitative data. An overview of the free text responses gathered via the questionnaire is given in Table 3.

\section{$\underline{\text { Insert Table } 3 \text { here }}$}

The text answers have been subject to a qualitative analysis using the software package NVivo. The central aim was to uncover common schemes that may give further insight into the attitudes and practices of the population surveyed. Lower level codes and higher-level categories were generated, allowing the extraction of key themes from the qualitative data available, similarly to a thematic analysis (Bryman, 2012).

A word frequency analysis of the comments on the questionnaire items grouped according to the clusters identified by the quantitative analysis has shown that in all the three clusters “data” was frequently repeated. Therefore all 265 comments have been analyzed with respect to how they relate to the concept of data.

Three schemes were identified (Fig. 5).

\section{Insert Fig 5 here}

Two of them give insight into the attitude of the respondents towards data as being enthusiastic or careful. The third summarizes the comments on data availability. This one 
was conceptually linked to remarks that comment on the quality of a cost estimate. For illustrative purposes Fig. 5 shows selected comments on the cost estimators’ attitude towards data. Comments that were assigned to the concept of data availability highlight the problem of gathering the required data or having data available in the appropriate format. Respondents linked this explicitly to the accuracy of an estimate. However there were also statements suggesting that "understanding of the system being estimated is the [most important] factor in accurate estimates”. This relates to a formal system representation as proposed in the questionnaire. In this regard, there were a number of comments suggesting a critical attitude towards the usage of data, as shown in Fig. 5.

In particular two comments highlighted the challenge identified in this paper: "Cost estimate architecture has to follow system architecture [...]”, which suggests that the cost estimator is/or at least should be aware of the system architecture to base the estimate upon. Practices however are stated as being different: “My experience is that while these System Engineering methods are useful from a procedural / architectural mapping perspective, I have never seen them used in the actual cost estimating process.” However, none of these comments explicitly relates the availability of data or the accuracy of an estimate to collaboration with other disciplines. Rather, “subject matter experts” are considered as “another source of historical data [...]”. The same respondent nevertheless acknowledges that experts "are better [than datasets] at providing cost data that applies to system to be delivered."

The absence of concepts related to collaboration other than identifying experts as sources of knowledge is interpreted as an indication for the respondents perceiving themselves mainly 
as collectors of data relevant to their needs. However, highly contrasting views on the reliability of data also emerge.

\section{DISCUSSION}

In the following the findings presented in the previous section are used to address the research questions.

The first component identified by the PCA seems to relate to RQ1 (whether representing and modeling a PSS is perceived as a precondition for a meaningful estimate the cost of the service outcomes provided). Respondents’ scores within this cluster of items suggest an overall unfavorable disposition of the respondents towards the idea that representing and modeling a PSS is a precondition to provide a meaningful estimate the cost of the service it provides. In line with most academic literature, the idea of having as the point of focus for the analysis a PSS delivering service outcomes rather than a product is still marginal. Respondents were likely to consider the cost of providing a service via PSS and the cost of the in-service stage of a durable product as conceptually equivalent.

The second component identified by the PCA appears to relate more closely to RQ2 (whether there is a counterpart in current cost estimating practice of the system approach underpinning the representation and modelling of a PSS). Based on the items included in this cluster, it seems that the term 'systems' is often used as a synonym for 'product', and that the structure of such systems is mostly a breakdown. However, terminological ambiguity played a major role in designing and conducting this survey, and despite the researcher's efforts (e.g., providing a glossary during the pilot survey) could not be entirely eliminated. 
From the items included in third component identified by the PCA, it seems difficult to answer either positively or negatively to RQ3 (whether cost estimators use their knowledge about the underpinning service delivery system along with data on product-related features). As the analysis of the free text field showed, System Engineering methods may be associated by the respondent to a procedural mapping, but not to the process of cost estimating. In the absence of a non-ambiguous understanding of PSS as a particular type of 'system' it is difficult to evaluate the importance of representing and modeling the PSS as a precondition to evaluating the cost of the service it provides. This 'grey' zone is probably worth further investigation, especially since claims of a 'system' approach is common in cost estimation, but such claims are seldom accompanied by a clear computational structure which shows how the system nature of the phenomenon of interest affects the way cost evaluation is carried out.

\section{CONCLUSIONS AND FURTHER WORK}

This paper has presented an exploratory research aimed to investigate how current cost estimating practice relates with the idea of having as the point of focus for the analysis a PSS delivering service outcomes, rather than a product.

Partly because the topic is in its infancy, and partly because an Internet survey has been used, this researcher has no aspiration to make definitive, generalizable claims. The reasons for this were discussed in the methodology section. Rather, it aims to look for initial patterns, ideas and hypotheses via an Internet survey.

As shown in the findings section, the scores given by the respondents to certain clusters of questionnaire items suggest a negative answer to the three research questions. Practitioners do not seem excessively destabilized by the concept of PSS. In line with the incumbent 
trend in the academic literature, the respondents would go about a PSS in the same way they would go about a product's 'in-service' phase. Since the concept of 'system' is often used as a synonym for 'product', it does not seem that a PSS is perceived as a system in its own right when the aim is to evaluate cost. This suggests a tendency to understand a PSS through the technical domain only, which reduces to the individual product component of a PSS. Less attention is paid the broader transformation system a product partakes to. However, the qualitative analysis of the comments revealed that the respondents were aware that the concept of PSS links with systems engineering and potentially requires exchange of knowledge that goes beyond mere data gathering and manipulation. The limitations of this research are mainly due to the use of a non-statistical sampling, and to the difficulty of avoiding non-response bias. The use of the online forms to advertise the survey allowing participants self-selection may also raise validity concerns. These aspects are to some extent endemic when using Internet surveys, nevertheless they considerably reduce the possibility to generalize the research findings beyond the sample. Despite its limitations, this research can provide impulse to the current debate by raising awareness that inconsistencies may arise if the concept of PSS is reduced to the products involved rather than considered as transformation system in its own right. For example, the nature of an availability-based contract suggests that the underpinning PSS must continuously deliver the contractually agreed service outcomes (e.g., aircraft on the apron in a fit state to fly). A cost evaluation that is meant to support those involved in the contract working together to achieve a common objective over time, rather than foster tensions and litigation, should reflect the ongoing nature of the work of a PSS, and the system nature of a PSS. There is, however, not a ready answer on how to go about it. To be 
ahead of their game, therefore, practitioners may found beneficial to consider the current challenges of representing and modeling a PSS, and how they may relate to the evaluation of the cost of the service outcome delivered by a PSS.

\section{REFERENCES}

Akintoye, A., \& Fitzgerald, E. (2000). A survey of current cost estimating practices in the UK: Construction Management and Economics. Construction Management and Economics, 18(2), 161-172.

Amos, S. J. (Ed.). (2004). Skills \& knowledge of cost engineering: A continuing project of the AACE International Education Board (5th ed. rev). Morgantown, WV: AACE International.

BAE Systems. (2009). Availability contracting.: MAS procurement handbook. Lancashire.

Baines, T., \& Lightfoot, H. (2013). Made to serve: How manufacturers can compete through servitization and product-service systems. Hoboken, N.J, Chichester: Wiley.

Barnette, J. J. (2007). Likert scaling. In N. Salkind (Ed.), Encyclopedia of measurement and statistics (pp. 715-719). Thousand Oaks, CA: SAGE.

Bartolomei, J. E., Hastings, D. E., Neufville, R. de, \& Rhodes, D. H. (2012). Engineering Systems Multiple-Domain Matrix: An organizing framework for modeling large-scale complex systems. Systems Engineering, 15(1), 41-61.

Battisti, G., \& Stoneman, P. (2010). How Innovative are UK Firms?: Evidence from the Fourth UK Community Innovation Survey on Synergies between Technological and Organizational Innovations. British Journal of Management, 21(1), 187-206. 
Belvedere, V., Grando, A., \& Bielli, P. (2013). A quantitative investigation of the role of information and communication technologies in the implementation of a product-service system. International Journal of Production Research, 51(2), 410-426.

Best, S. J., \& Harrison, C. H. (2009). Internet Survey Methods. In L. Bickman \& D. J. Rog (Eds.), The SAGE handbook of applied social research methods (2nd ed., pp. 413-435). Los Angeles, London: SAGE.

Best, S. J., \& Krueger, B. S. (2008). Internet Survey Design. In N. Fielding, R. M. Lee, \& G. Blank (Eds.), The SAGE Handbook of Online Research Methods (pp. 217-236). London: SAGE.

Blank, G. (2008). Online Research Methods and Social Theory. In N. Fielding, R. M. Lee, \& G. Blank (Eds.), The SAGE Handbook of Online Research Methods (pp. 537-550). London: SAGE.

Blessing, L. T. M., \& Chakrabarti, A. (2009). DRM, a design research methodology. Heidelberg: Springer.

Bryman, A. (2012). Social research methods (4th ed.). Oxford: Oxford University Press. BS ISO/IEC (2002): BS ISO/IEC 15288:2002 Systems engineering - System life cycle processes. London: BSI.

Caldwell, N. D., \& Settle, V. (2011). Incentives and contracting for availability: procuring complex performance. In I. C. L. Ng, G. C. Parry, P. Wild, D. McFarlane, \& P. Tasker (Eds.), Complex engineering service systems. Concepts and research (pp. 147-160). Berlin: Springer.

Cavalieri, S., \& Pezzotta, G. (2012). Product-Service Systems Engineering: State of the art and research challenges. Computers in Industry, 63(4), 278-288. 
Charnley, F., Lemon, M., \& Evans, S. (2011). Exploring the process of whole system design. Design Studies, 32(2), 156-179.

Coleman, J. S. M. (2010). Principal Components Analysis. In N. J. Salkind (Ed.), Encyclopedia of research design . Los Angeles: SAGE.

Curran, R., Raghunathan, S., \& Price, M. (2004). Review of aerospace engineering cost modelling: The genetic causal approach. Progress in Aerospace Sciences, 40(8), 487534.

Datta, P. P., \& Roy, R. (2010). Cost modelling techniques for availability type service support contracts: A literature review and empirical study. CIRP Journal of Manufacturing Science and Technology, 3(2), 142-157.

Denscombe, M. (2010). The good research guide: For small-scale social research projects (4th ed.). Maidenhead: McGraw-Hill/Open University Press.

Dunteman, G. H. (1989). Principal components analysis. Sage university papers series. Quantitative applications in the social sciences: no. 07-069. Newbury Park: SAGE.

Field, A. (2005). Discovering statistics using SPSS: (and sex, drugs and rock ' $n$ ' roll) (2nd ed.). London: SAGE.

Field, F., Kirchain, R., \& Roth, R. (2007). Process cost modeling: Strategic engineering and economic evaluation of materials technologies. JOM Journal of the Minerals, Metals and Materials Society, 59(10), 21-32.

Fielding, J. P. (1999). Introduction to aircraft design. Cambridge: Cambridge University Press. 
Fox, J. (2010). polycor: Polychoric and Polyserial Correlations. $R$ package version 0.7-8. Retrieved from http://CRAN.R-project.org/package=polycor

Fricker, R. D. (2008). Sampling Methods for Web and E-mail Surveys. In N. Fielding, R. M. Lee, \& G. Blank (Eds.), The SAGE Handbook of Online Research Methods (pp. 195217). London: SAGE.

Hart, C. G., He, Z., Sbragio, R., \& Vlahopoulos, N. (2012). An advanced cost estimation methodology for engineering systems. Systems Engineering, 15(1), 28-40.

Harvey, J. (Ed.). (1998). Evaluation cookbook. Edinburgh: Institute for Computer Based Learning.

Hawkins, F. H., \& Orlady, H. W. (1993). Human factors in flight (2nd ed.). Aldershot: Ashgate.

Hernandez-Pardo, R. J. (2013). Exploring SME Perceptions of Sustainable Product Service Systems. IEEE Transactions on Engineering Management, 60(3), 483-496.

Huang, X., Newnes, L. B., \& Parry, G. C. (2012). The adaptation of product cost estimation techniques to estimate the cost of service. International Journal of Computer Integrated Manufacturing, 25(4-5), 417-431.

Jiao, J., \& Tseng, M. M. (1999). A pragmatic approach to product costing based on standard time estimation. International Journal of Operations \& Production Management, 19(7), 738-755.

Keller, S., Collopy, P., \& Componation, P. (2014). What is wrong with space system cost models?: A survey and assessment of cost estimating approaches. Acta Astronautica, 93, 345-351. 
Manfreda, K. L., Berzelak, J., Vehovar, V., Bosnjak, M., \& Haas, I. (2008). Web surveys versus other survey modes: A meta-analysis comparing response rates. International Journal of Market Research, 50(1), 79-104.

Massart, D. L., Smeyers-Verbeke, J., Capron, X., \& Schlesier, K. (2005). Visual Presentation of Data by Means of Box Plots. LC•GC Europe, 18(4), 215-218.

Meier, H., Roy, R., \& Seliger, G. (2010). Industrial Product-Service Systems—IPS2. CIRP Annals - Manufacturing Technology, 59(2), 607-627.

Pallant, J. (2010). SPSS survival manual (4th ed.). Maidenhead: McGraw Hill.

Panter, A. T., Swygert, K. A., Grant Dahlstrom, W., \& Tanaka, J. S. (1997). Factor Analytic Approaches to Personality Item-Level Data. Journal of Personality Assessment, 68(3), 561-589.

Parry, G. (2012). Servitisation and value co-production in the UK music industry: An empirical study of Consumer Attitudes. International Journal of Production Economics, 135(1), 320-333.

Phumbua, S., \& Tjahjono, B. (2012). Towards product-service systems modelling: a quest for dynamic behaviour and model parameters. International Journal of Production Research, 50(2), 425-442.

R Development Core Team. (2012). R: A Language and Environment for Statistical Computing. Vienna, Austria. Retrieved from http://www.R-project.org/

Roy, R., \& Erkoyuncu, J. A. (2011). Service cost estimation challenges in Industrial Product-Service Systems. In J. Hesselbach \& C. Herrmann (Eds.), Functional thinking for value creation. Proceedings of the 3rd CIRP International Conference on Industrial Product Service Systems (pp. 1-10). Berlin Heidelberg: Springer-Verlag. 
Roy, R. (2003). Cost engineering: why, what and how? Decision Engineering Report Series, Cranfield University, Cranfield, UK.

Serpell, A. F. (2004). Towards a knowledge-based assessment of conceptual cost estimates. Building Research \& Information, 32(2), 157-164.

Settanni, E., Newnes, L. B., Thenent, N. E., Parry, G. C., \& Goh, Y. M. (2014). A Throughlife costing methodology for use in Product-Service-Systems. International Journal of Production Economics, 153, 161-177.

Shih, T.-H., \& Xitao Fan. (2008). Comparing Response Rates from Web and Mail Surveys: A Meta-Analysis. Field Methods, 20(3), 249-271.

Stewart, R. D. (1982). Cost estimating. New York: Wiley.

Sue, V. M., \& Ritter, L. A. (2007). Conducting online surveys. Los Angeles: SAGE.

Tukker, A. (2013). Product services for a resource-efficient and circular economy - a review. Journal of Cleaner Production. Advance online publication. doi:10.1016/j.jclepro.2013.11.049

Tukker, A., \& Tischner, U. (2006). Product-services as a research field: past, present and future.: Reflections from a decade of research. Journal of Cleaner Production, 14(17), 1552-1556.

Tysseland, B. E. (2008). Life cycle cost based procurement decisions. International Journal of Project Management, 26(4), 366-375.

Valerdi, R. (2011). Heuristics for Systems Engineering Cost Estimation: Systems Journal, IEEE. Systems Journal, IEEE, 5(1), 91-98. 
Vasantha, G. V. A., Roy, R., Lelah, A., \& Brissaud, D. (2011). A review of product-service systems design methodologies. Journal of Engineering Design, 23(9), 635-659.

Vehovar, V., \& Lozar Manfreda, K. (2008). Overview: Online Surveys. In N. Fielding, R. M. Lee, \& G. Blank (Eds.), The SAGE Handbook of Online Research Methods (pp. 176195). London: SAGE.

Vogt, W. P. (2005). Dictionary of Statistics \& Methodology. (3rd). Thousand Oaks, CA: SAGE.

Wang, G., Valerdi, R., Roedler, G. J., Ankrum, A., \& Gaffney, J. E. (2012). Harmonising software engineering and systems engineering cost estimation. International Journal of Computer Integrated Manufacturing, 25(4-5), 432-443.

Watkins, M. W. (2006). Determining Parallel Analysis Criteria. Journal of Modern Applied Statistical Methods, 5(2), 344-346.

Weems, G. (2007). Reverse scaling. In N. Salkind (Ed.), Encyclopedia of measurement and statistics (pp. 844-847). Thousand Oaks, CA: SAGE. 


\section{Online questionnaire}

Q01

Q02

Q03

Q.04

Q05

Q06

(1)

Cosidit dryer. If, in the early stage you have access to a formal representation of that PSS - e.g., IDEF0, Service
Blueprint etc. - you will choose NOT to infer its cost from the available historical datasets about say, generic
hand dryers.

Q07 In order to generate cost estimates which are useful for decision making the cost engineer should be continuously involved in the evolving understanding of the system investigated - e.g., how a service is supposed to be delivered, how a product is meant to be used/operated, who is supposed to do what, how they interact etc.

Q08 At the early design stage there is no other feasible way to estimate the cost of a new product than inferring it statistically from the features and cost of existing products.

Q09 Assume that the delivery of a number of "dried pairs of hands" over a certain period is a Product-Service-System (PSS). To estimate the cost of such a PSS is NOT to estimate the cost of e.g., a hand dryer (a product) and, separately that of its expected maintenance/repair (a service) over that period.

Q10 To estimate the cost of a system means to estimate the cost of a long-life product (aircraft, car etc.) by HIERARCHICALLY breaking it down into its components (sub-systems).

Q11 To best estimate the cost of a service you WILL NOT consider such a service as being a system of interlinked activities performed by both the service provider and the service receiver.

Q12 When you estimate the cost of a new PRODUCT from existing products you expect to RETRIEVE (e.g. from a handbook, ask an expert, browse a database) the latter's cost and any other measurable feature you need.

Q13 The cost of a service can be inferred from measurable features of such service. For example, if the service is "machine repair", such features include the distance between the machine provider and the customer, number of call outs for repair services etc.

Q14 If the object of cost estimation is a Product Service System - not an individual product or service - then the transparent and regular integration of system modeling with cost estimation is crucial in order to improve usefulness of a cost estimate for decision making.

Q15 In estimating the through life cost of a product, its performance through-life can be studied through selected “designed-in” features, such as Mean Time Between Failures, Mean Time To Repair, etc.

Q16 The through-life cost of a Product Service System (e.g., selling painted car bodies instead of a painting line), can be determined by selected characteristics of the PRODUCT involved (e.g., the painting line) such as its failure rates, mean time to repair, availability of spares etc.

Q17 The use of different cost estimation techniques (e.g., parametric, analytical, etc.) is required for different life cycle stages in order to estimate the cost of a product through-life (e.g., design, production, utilization etc.). 


\section{Online questionnaire}

Q18 Please select what you think are the most important aspects for selecting the cost estimating techniques to be used at each stage.

1. Availability of data

2. Ability to represent the system formally (e.g., by means of networks, Service Blueprints, etc.)

3. Ease of use of techniques and software

4. Availability of software packages

5. Computations follow well-known mathematical rules e.g., regression etc.

6. Familiarity with the technique

7. Acceptance of the technique within organizations

8. No opinion

Assume that cost estimates for different lifecycle stages of a product have been obtained using different techniques (parametric, activity-based costing, case-based reasoning). These figures are hardly comparable (e.g., for validation purposes) because each technique used is based on different assumptions, logics and computationa mechanisms.

The claim that most of the through-life cost of a product (say for example between 65-85\%) is "locked-in" at the early design stages is an assumption with little or no practical evidence.

Most of (say e.g., 65-85\%) the through-life cost of a Product Service System (PSS) is locked-in at the PRODUCT design stage. So if the Product Service System is e.g., the provision of the availability of an aircraft, most of its through-life cost is locked-in when the aircraft is designed.

The claim that most of a product's life-cycle cost (65-85\%) is locked-in at the design stage shifts the entire focus of cost reduction on product design, neglecting the actions that can be taken at other stages.

Because a great portion (say 65-85\%) of a long-life product (e.g., aircraft) through-life cost OCCURS while inservice, it is justified to focus on that stage when estimating costs through-life, and take the cost of other stages (e.g., manufacturing) as given.

When estimating the cost of a "system" NOT ONLY do you identify multiple organized elements (either tangible as e.g., the engines, avionics, fuselage, etc. of an aircraft or intangible as e.g., activities), BUT you ALSO specify how they interact to accomplish a specific purpose. 
Table 1 Descriptive statistics

\begin{tabular}{|c|c|c|c|c|c|c|c|c|c|c|c|c|c|c|c|c|c|c|c|c|c|c|c|c|}
\hline & & Q01 & Q02 & Q03 & $\begin{array}{l}\text { Q04 } \\
\text { R }\end{array}$ & $\begin{array}{c}\text { Q05 } \\
\text { R }\end{array}$ & $\begin{array}{c}\text { Q06 } \\
\text { R }\end{array}$ & $\begin{array}{l}\text { Q07 } \\
\text { R }\end{array}$ & Q08 & $\begin{array}{c}\text { Q09 } \\
\text { R }\end{array}$ & Q10 & Q11 & Q12 & Q13 & $\begin{array}{c}\text { Q14 } \\
\text { R }\end{array}$ & Q15 & Q16 & Q17 & $\begin{array}{l}\text { Q19 } \\
\text { R }\end{array}$ & $\begin{array}{l}\text { Q20 } \\
\text { R }\end{array}$ & Q21 & $\begin{array}{c}\text { Q22 } \\
\text { R }\end{array}$ & Q23 & $\begin{array}{c}\text { Q24 } \\
\text { R }\end{array}$ \\
\hline \multirow{2}{*}{$\begin{array}{l}\text { Observati } \\
\text { ons }\end{array}$} & Valid & 127 & 126 & 120 & 118 & 117 & 111 & 108 & 108 & 106 & 104 & 104 & 103 & 101 & 99 & 99 & 98 & 98 & 98 & 98 & 98 & 98 & 97 & 97 \\
\hline & Missing & 11 & 12 & 18 & 20 & 21 & 27 & 30 & 30 & 32 & 34 & 34 & 35 & 37 & 39 & 39 & 40 & 40 & 40 & 40 & 40 & 40 & 41 & 41 \\
\hline \multirow[t]{5}{*}{ Frequency } & 1 & 40.2 & 2.4 & 12.5 & 0 & 0 & 2.7 & 0 & 3.7 & 5.7 & 22.1 & 1.0 & 18.4 & 13.9 & 1.0 & 22.2 & 11.2 & 32.7 & 7.1 & 11.2 & 13.3 & 4.1 & 6.2 & 1.0 \\
\hline & 2 & 44.1 & 14.3 & 35.8 & 6.8 & 9.4 & 41.4 & 4.6 & 38.0 & 30.2 & 53.8 & 20.2 & 62.1 & 67.3 & 0 & 63.6 & 62.2 & 51.0 & 45.9 & 27.6 & 53.1 & 30.6 & 22.7 & 6.2 \\
\hline & 3 & 10.2 & 40.5 & 10.8 & 8.5 & 15.4 & 29.7 & 1.9 & 16.7 & 27.4 & 13.5 & 20.2 & 9.7 & 12.9 & 16.2 & 11.1 & 14.3 & 11.2 & 15.3 & 33.7 & 24.5 & 17.3 & 20.6 & 14.4 \\
\hline & 4 & 4.7 & 34.1 & 35.8 & 55.9 & 54.7 & 23.4 & 36.1 & 33.3 & 30.2 & 9.6 & 41.3 & 8.7 & 5.9 & 62.6 & 2.0 & 11.2 & 5.1 & 24.5 & 23.5 & 8.2 & 39.8 & 36.1 & 63.9 \\
\hline & 5 & .8 & 8.7 & 5.0 & 28.8 & 20.5 & 2.7 & 57.4 & 8.3 & 6.6 & 1.0 & 17.3 & 1.0 & 0 & 20.2 & 1.0 & 1.0 & 0 & 7.1 & 4.1 & 1.0 & 8.2 & 14.4 & 14.4 \\
\hline \multicolumn{2}{|l|}{ Median } & 2.0 & 3.0 & 3.0 & 4.0 & 4.0 & 3.0 & 5.0 & 3.0 & 3.0 & 2.0 & 4.0 & 2.0 & 2.0 & 4.0 & 2.0 & 2.0 & 2.0 & 2.0 & 3.0 & 2.0 & 3.0 & 4.0 & 4.0 \\
\hline \multicolumn{2}{|c|}{ Mode } & 2.0 & 3.0 & $2^{\mathrm{a}}$ & 4.0 & 4.0 & 2.0 & 5.0 & 2.0 & 2.00 & 2.0 & 4.0 & 2.0 & 2.0 & 4.0 & 2.0 & 2.0 & 2.0 & 2.0 & 3.0 & 2.0 & 4.0 & 4.0 & 4.0 \\
\hline \multicolumn{2}{|c|}{ Inter Quartile Range } & 1.0 & 1.0 & 2.0 & 1.0 & 0.5 & 2.0 & 1.0 & 2.0 & 2.0 & 0.0 & 1.0 & 0.0 & 0.0 & 0.0 & 0.0 & 1.0 & 1.0 & 2.0 & 2.0 & 1.0 & 2.0 & 2.0 & 0.0 \\
\hline
\end{tabular}


Table 2 Components interpretation and scale reliability

\begin{tabular}{|c|c|c|c|}
\hline Component & Underlying topics & Items included & $\begin{array}{l}\text { Chronbach's } \\
\text { Alpha }\end{array}$ \\
\hline 1 & $\begin{array}{l}\text { Disposition toward adaptation of feature-centered } \\
\text { methods in cost estimations (favorable scores less) }\end{array}$ & $\begin{array}{l}\text { Q01**; Q12; Q13; } \\
\text { Q15; Q16; Q17* }\end{array}$ & .629 \\
\hline 2 & $\begin{array}{l}\text { Disposition toward system understanding through } \\
\text { reduction/isolation (favorable scores less) }\end{array}$ & $\begin{array}{l}\text { Q02; Q03; } \\
\text { Q04_R**; Q07_R; } \\
\text { Q08; Q10**; Q11; } \\
\text { Q14_R**; Q23 }\end{array}$ & .626 \\
\hline 3 & $\begin{array}{l}\text { Disposition toward endorsing common practice and } \\
\text { assumptions in cost estimation (favorable scores less) }\end{array}$ & $\begin{array}{l}\text { Q05_R; Q06_R; } \\
\text { Q09_R; Q19_R*; } \\
\text { Q20_R**; Q22_R; } \\
\text { Q24_R; }\end{array}$ & .594 \\
\hline
\end{tabular}

Note: $*$ = loading below $.512 ; * *=$ loading below .4 
Table 3. Summary of free text responses

\begin{tabular}{ll}
\hline Percentage of respondents leaving at least one comment & $61 \%$ \\
\hline Number of comments analyzed & 265 \\
Number of comment per topic & \\
Feature-based approach & 76 \\
System understanding by reduction & 88 \\
Endorsement of common practices & 80 \\
\hline
\end{tabular}

4 


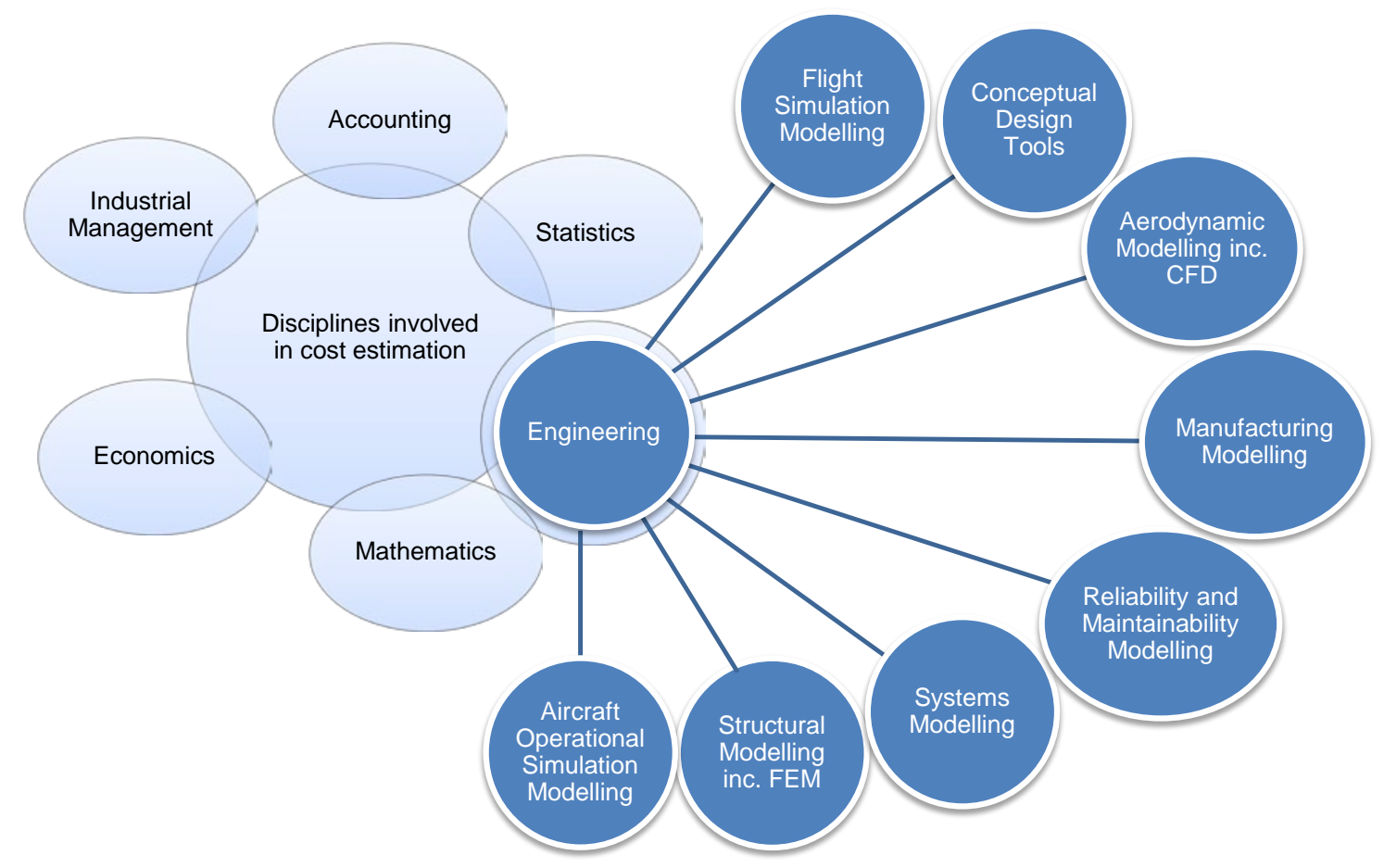

Figure 1 Interdisciplinary aspect of cost engineering using aircraft as an example (based on (Curran et al., 2004; Fielding, 1999, p. 141) and (Stewart, 1982)) 

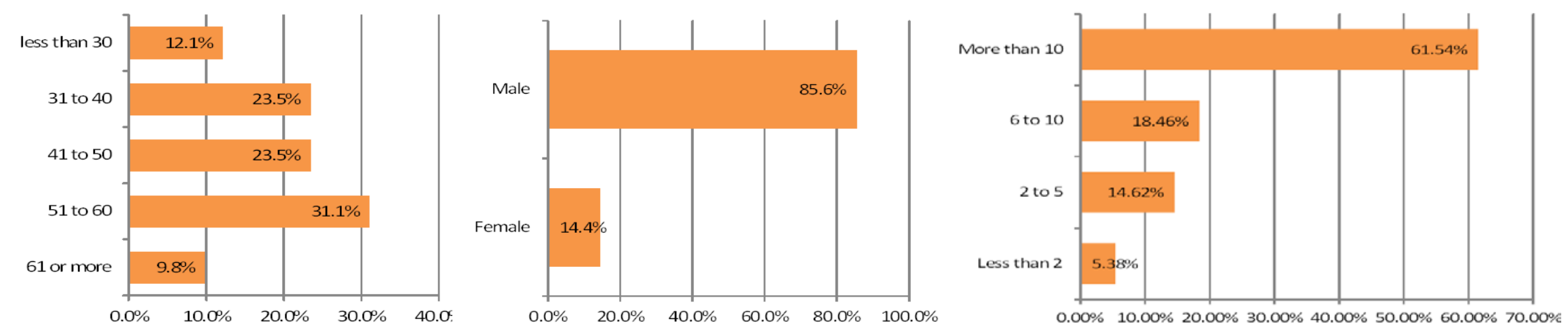

(a)

(b)

(c)

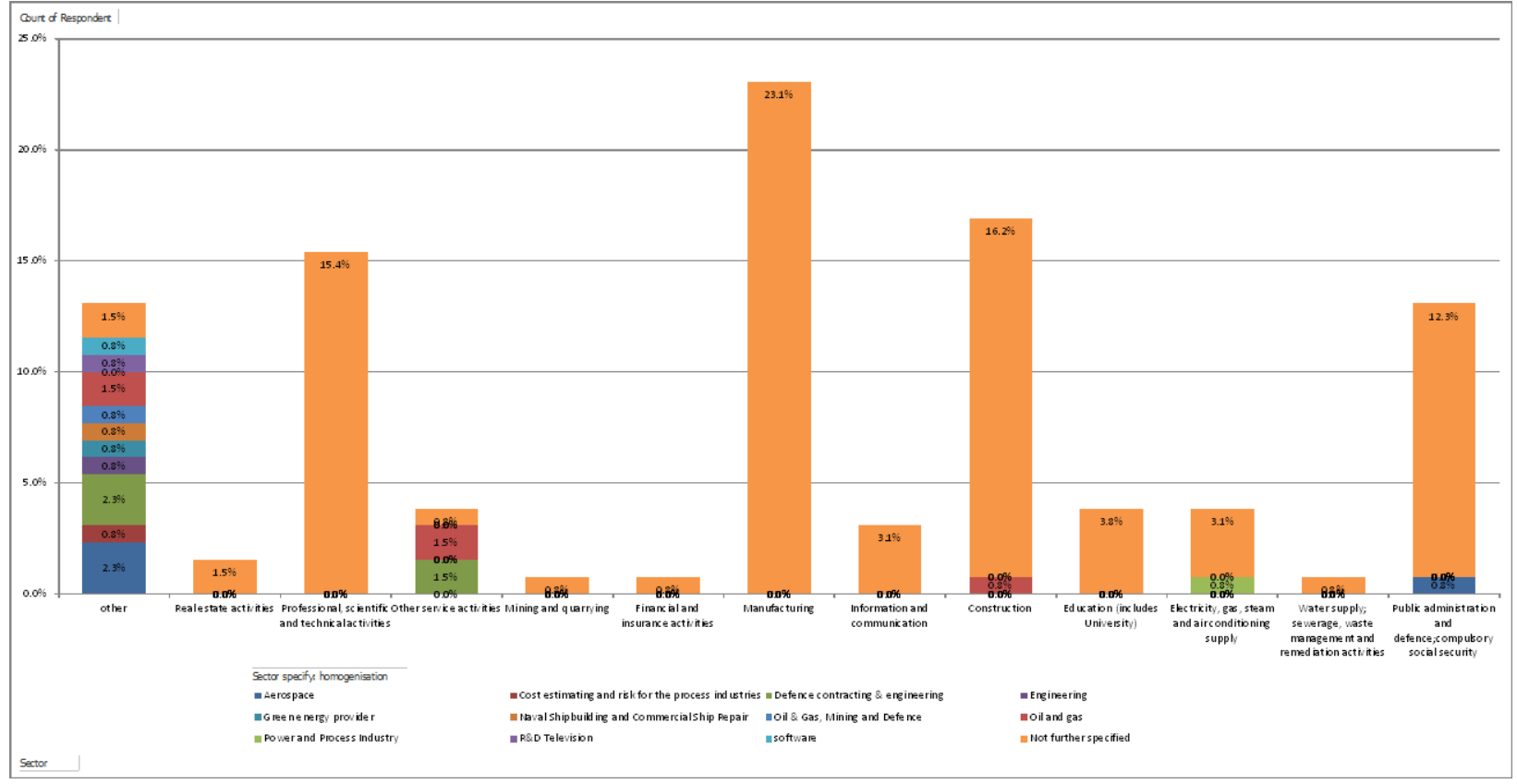

(d)

Figure 2 Respondents information: (a) age; (b) gender; (c) expertise; (d) sector 


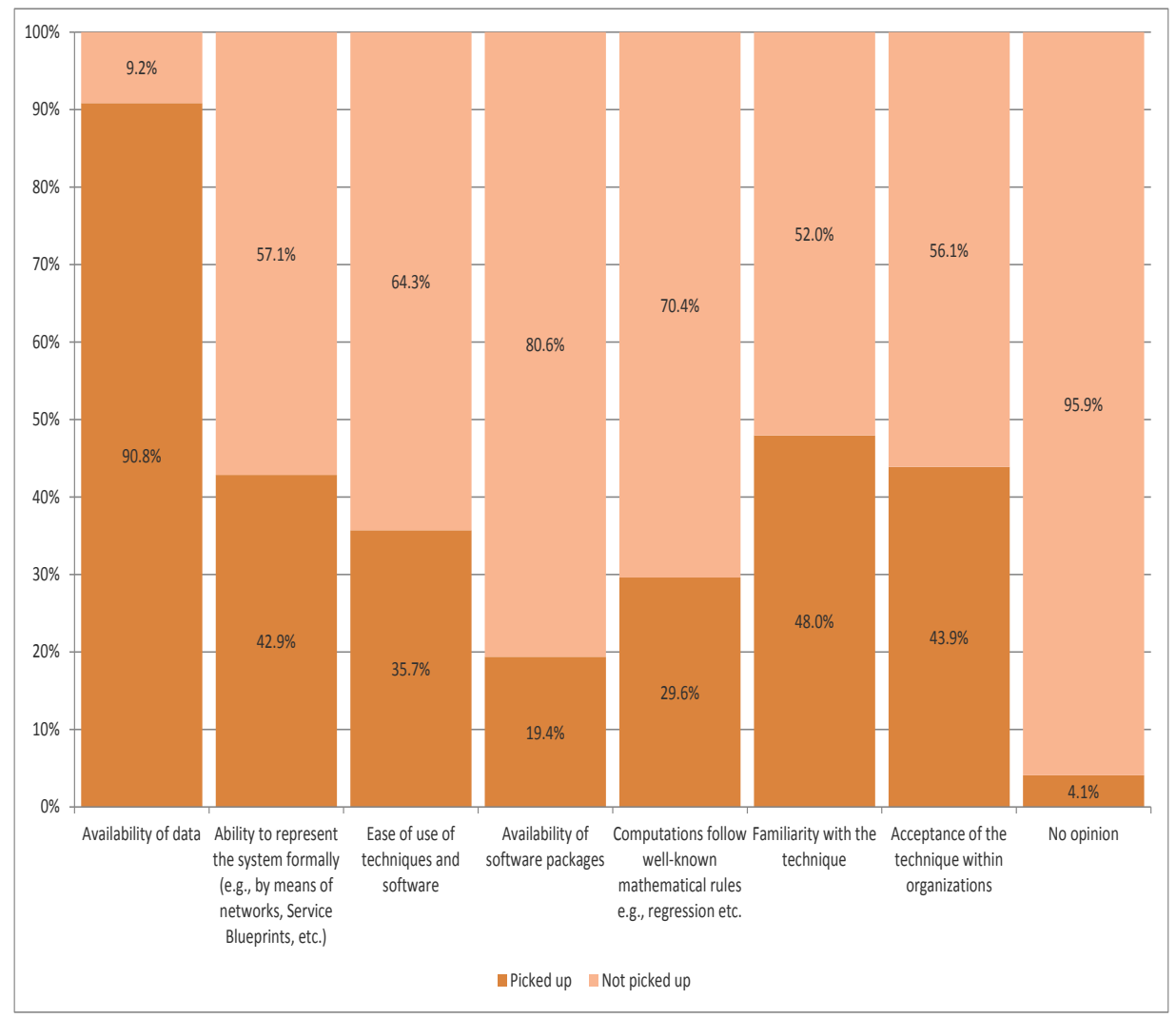

Figure 3: Answer to the 'select all that apply' question 


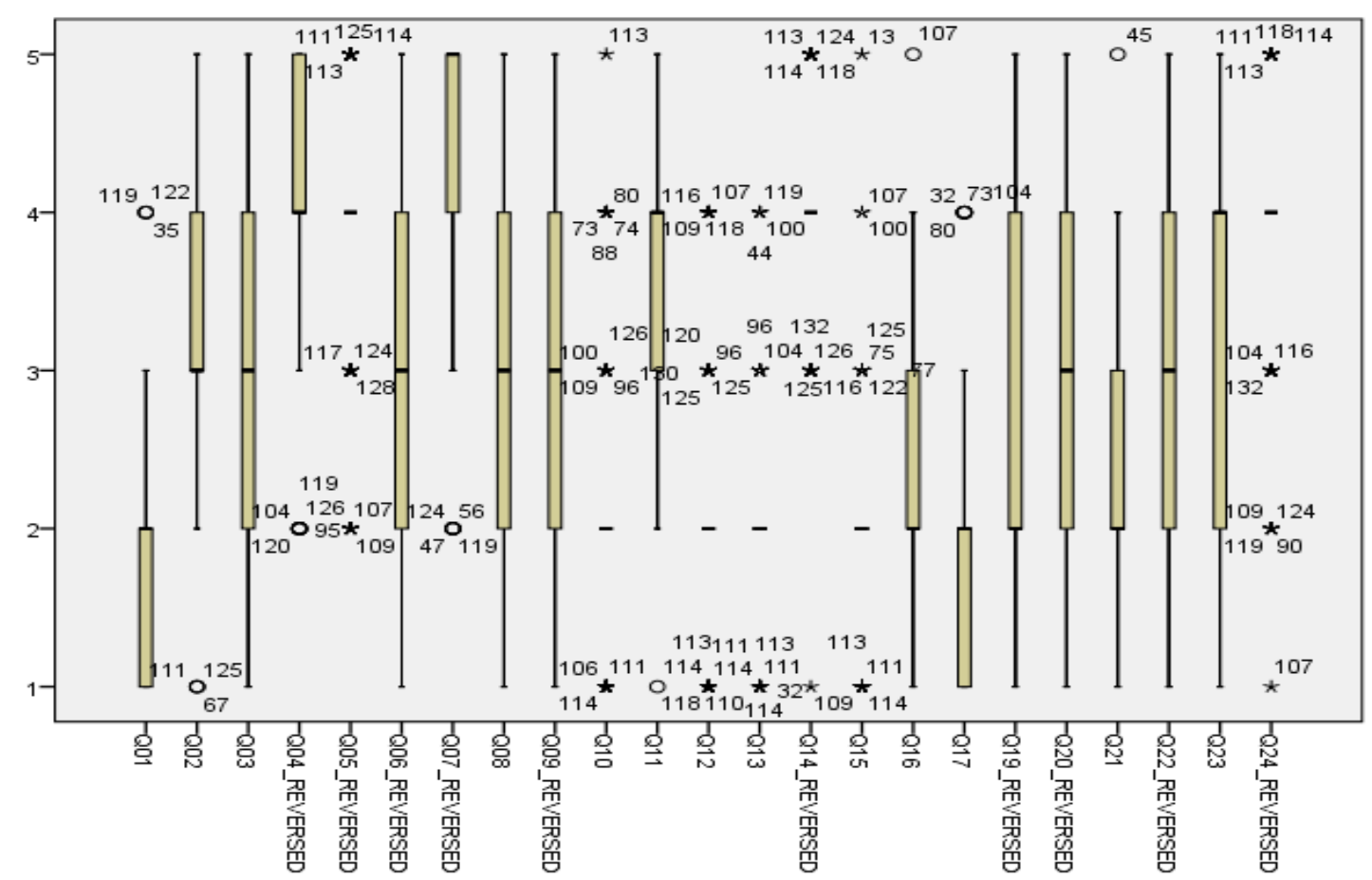

Figure 4 Box plots for each items in the questionnaire. Points are outliers, asterisks are extreme outliers. Numbers indicate the respondents who are outliers. 


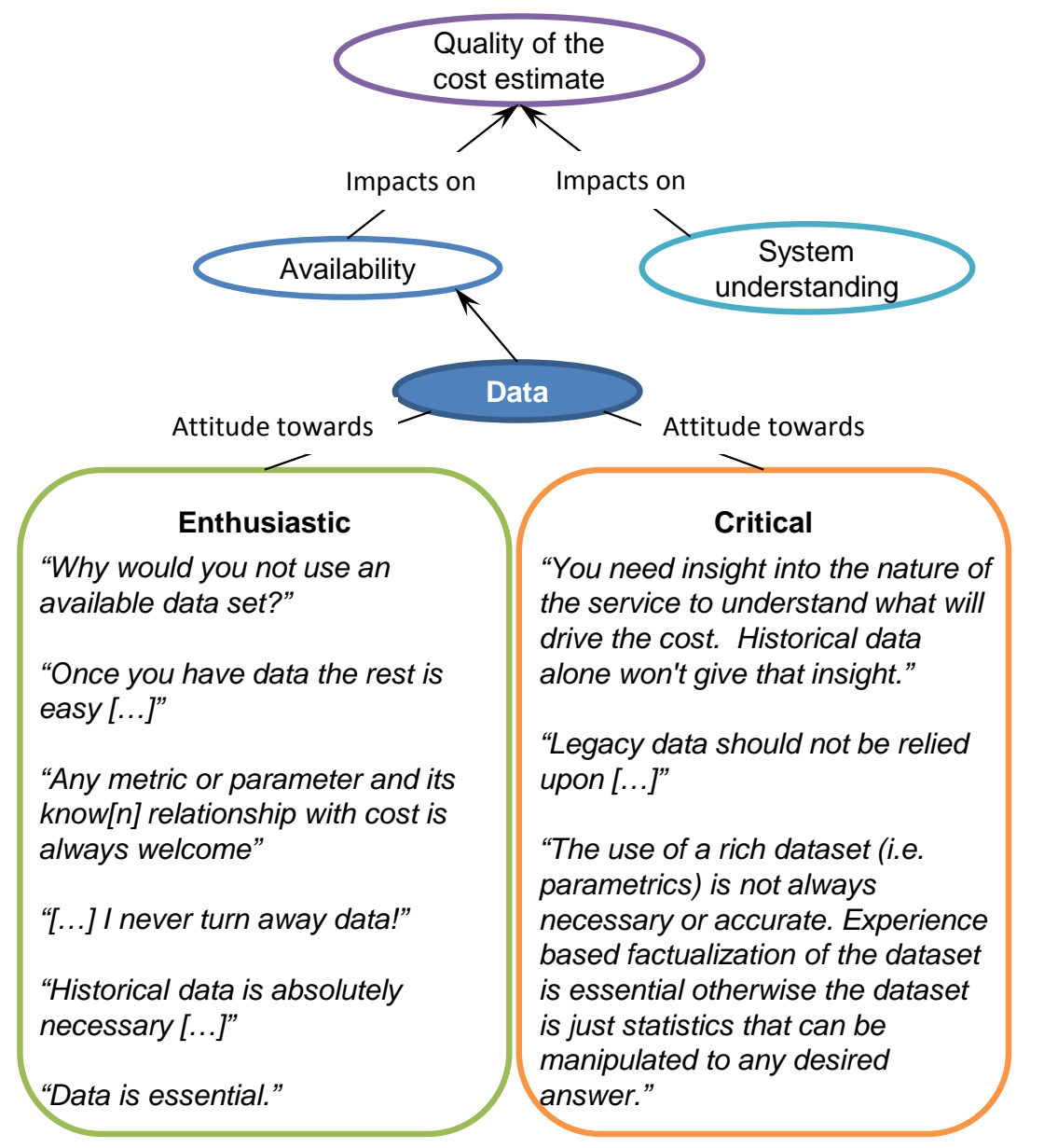

Fig. 5. Concepts derived from the core concept “data”, showing different attitudes and the link to the quality of a cost estimate 